\title{
Correction to: Task-evoked pupillary responses track effort exertion: Evidence from task-switching
}

\author{
Kevin da Silva Castanheira ${ }^{1}$ - Sophia LoParco ${ }^{2}$ A. Ross Otto ${ }^{1}$
}

Published online: 2 December 2020

(C) The Psychonomic Society, Inc. 2020

\section{Correction to: Cogn Affect Behav Neurosci https://doi.org/10.3758/s13415-020-00843-Z}

The original article has been corrected. The second author name was changed to Sophia LoParco in the author list. The details given in this erratum are correct.

The online version of the original article can be found at https://oi.org/ 10.3758/s13415-020-00843-Z

$\triangle$ A. Ross Otto ross.otto@megill.ca

1 Department of Psychology, McGill University, Montréal, Canada

2 Intergrated Program in Neuroscience, McGill University, Montréal, Canada 